\title{
Tissue Culture Methods for the Screening and Analysis of Putative Virus-Resistant Transgenic Potato Plants
}

\author{
P. Russo and S. A. Slack
}

Department of Plant Pathology, Cornell University, Ithaca, NY 14853.

Accepted for publication 21 January 1998.

\begin{abstract}
Russo, P., and Slack, S. A. 1998. Tissue culture methods for the screening and analysis of putative virus-resistant transgenic potato plants. Phytopathology 88:437-441.

Following regeneration, putative virus-resistant transgenic plants are usually transferred from tissue culture to a greenhouse or growth chamber to screen for resistance to infection and disease development using mechanical, graft, or insect vector inoculation methods. To reduce initial screening costs and time, we developed mechanical and graft inoculation methods suitable for tissue culture use. The in vitro methods were validated by comparing them with similar greenhouse screens using putative potato virus $\mathrm{Y}$ strain o $\left(\mathrm{PVY}^{\circ}\right)$ replicase-mediated resistant regenerants

of the potato cultivar Atlantic. Five transgenic lines were tested, with similar results obtained from in vitro and greenhouse experiments. Two of the transgenic lines, $\mathrm{A} 1$ and $\mathrm{A} 3$, showed the greatest resistance to $\mathrm{PVY}{ }^{\circ}$ infection, as indicated by low enzyme-linked immunosorbent assay values and infection rates. In vitro mechanical inoculation methods were also used to infect wild-type tomato and tobacco plants with cucumber mosaic virus and potato virus Y. Potato plants were also infected with the phloemrestricted potato leafroll virus, a low-titer virus, using in vitro graft inoculation methods. These results suggest the potential usefulness of these simple, effective, and economical techniques for screening large numbers of putative virus-resistant plants.
\end{abstract}

The stable insertion of recombinant DNA molecules into plant genomes and subsequent gene expression has become a routine way of transferring new genetic traits into many plant species $(5,9,14)$. Although there are several methods by which recombinant DNA can be introduced into plants, e.g., Ti-Agrobacterium-based plasmids (6), electroporation (2), or particle bombardment (11), most depend on tissue culture regeneration of transformed calli to produce transgenic plants (4). Putative transgenic plants are usually transplanted from tissue culture to a greenhouse or growth chamber for transgene expression screening (e.g., resistance to pathogens or herbicides, expression of foreign proteins of economic importance, etc.), which often involves testing many lines because transgene expression varies among transformants. The move from in vitro to greenhouse conditions causes an increase in time and cost for the analysis of transgenic plants, many of which usually do not pass preliminary screening tests.

In this study, we tested the usefulness of different inoculation methods performed on plants in tissue culture for the initial screening of putative potato virus $\mathrm{Y}$ strain o $\left(\mathrm{PVY}^{\circ}\right)$ replicase-mediated resistant transgenic potato plants. Performing the initial screening of transgenic plants in vitro provides a number of advantages: eliminates the time and materials necessary for transplanting in vitro plantlets to the greenhouse; decreases space requirements for propagation and maintenance of lines; provides a more easily controlling growth environment than a greenhouse (i.e., less prone to pest hazards and variations in light and temperature); needs fewer man-hours for manipulating plants in vitro; all of which translate into overall cost reductions.

\section{MATERIALS AND METHODS}

Plants and media. Potato (Solanum tuberosum L.) cultivar Atlantic was transformed with plasmid pKYLX-NIb, which is a de-

Corresponding author: P. Russo; E-mail address: par11@cornell.edu

Publication no. P-1998-0309-01R

(C) 1998 The American Phytopathological Society rivative of pKYLX (12), containing the entire $\mathrm{PVY}^{\circ}$ nuclear inclusion b (NIb) replicase protein coding region (1). Construction of pKYLX-NIb, transformation of potato cultivars, and molecular analysis of transformants (P. Russo, M. Zaitlin, and S. A. Slack, unpublished data) utilized Agrobacterium binary vector transformation (7), selection on kanamycin regeneration media (3), and reverse transcription-linked polymerase chain reaction for analysis of NIb gene expression (8). Tomato (Lycopersicon esculentum), tobacco (Nicotiana tabacum, Turkish cultivar Samsun NN), and 'Atlantic' plants were grown in tissue culture (in vitro) in modified Murashige and Skoog (MS) media: $4.3 \mathrm{~g}$ of MS basal salts (M-5524; Sigma Chemical Co., St. Louis), $0.4 \mathrm{mg}$ of thiamine$\mathrm{HCl}, 0.1 \mathrm{~g}$ of inositol, $30 \mathrm{~g}$ of sucrose, $0.17 \mathrm{~g}$ of $\mathrm{NaH}_{2} \mathrm{PO}_{4} \cdot \mathrm{H}_{2} \mathrm{O}$, and $2.5 \mathrm{~g}$ of Phytagel (P8169; Sigma Chemical Co.) per 1 liter of distilled $\mathrm{H}_{2} \mathrm{O}\left(\mathrm{dH}_{2} \mathrm{O}\right), \mathrm{pH}$ 6.0. The media was dispensed into $20 \times$ 150-mm Pyrex culture tubes (99445-20; Corning Glass Inc., Corning, NY), $9 \mathrm{ml}$ per tube, that were capped with plastic caps (73660; Kimble Glass, Vineland, NJ) and autoclaved. Nodal cuttings, one per MS tube, from tissue-cultured potato, tomato, and tobacco plants were made by aseptic techniques in a laminar flow hood. All in vitro plantlets were grown at room temperature (20 to $22^{\circ} \mathrm{C}$ ) with $16 \mathrm{~h}$ of light per day under fluorescent tubes, except for tomato, which required $12 \mathrm{~h}$ of light. All plants grown in the greenhouse were maintained at approximately 18 to $22^{\circ} \mathrm{C}$, with $16 \mathrm{~h}$ of light per day. Virus inocula were produced from infected plants maintained in vitro, i.e., $\mathrm{PVY}^{\circ}$ and potato leafroll virus (PLRV) in potatoes 'Mex SS 1035' and 'Russet Burbank', respectively, and cucumber mosaic virus strain Fast New York (Fny-CMV) in tobacco 'Samsun NN'.

Inoculation methods. Mechanical inoculation of in vitro plantlets was performed aseptically using a glass rod that had the abrasive silicon carbide (Aldrich Chemical Co., Milwaukee, WI) fused to one end (Fig. 1). Rods were made by heating glass rods (diameter 2 to $3 \mathrm{~mm}$, length 18 to $20 \mathrm{~cm}$ ) in a gas flame until soft, and then immediately rolling them in silicon carbide (mesh 250 to 400) using sufficient pressure to imbed the abrasive into the molten glass. This melting and imbedding was repeated four to five times 
until approximately $10 \mathrm{~mm}$ of the rod's end was covered. The rod was allowed to cool at room temperature, after which unembedded abrasive was removed. Such inoculating rods can be used repeatedly and sterilized by autoclaving or flamed using ethanol.

Sources of virus inocula came from infected plants maintained in vitro. These plants were generated by either disinfecting known virus-infected plant cuttings from the greenhouse (1 min in $70 \%$ ethanol, $10 \mathrm{~min}$ in $10 \%$ bleach plus $0.01 \%$ Tween-20, and $1 \mathrm{~min}$ in $70 \%$ ethanol, and then rinsed in sterile $\mathrm{dH}_{2} \mathrm{O}$ and placed in MS media), or by inoculating healthy tissue culture plants with purified virus as described below. Sap extracts from virus-infected plants were diluted 1:5 in phosphate buffer, $\mathrm{pH} 7.4$, and then centrifuged $(10,000 \times g)$ for $2 \mathrm{~min}$. The supernatant was passed through a $0.22-\mu$ filter to remove any bacterial and fungal contaminants. Mechanical inoculations were done aseptically in a laminar flow hood using plantlets with five to seven leaves. The silicon carbide end of a sterile rod was dipped into the filter-sterilized sap extract and then rubbed over the surface of three leaflets. Rods were rinsed

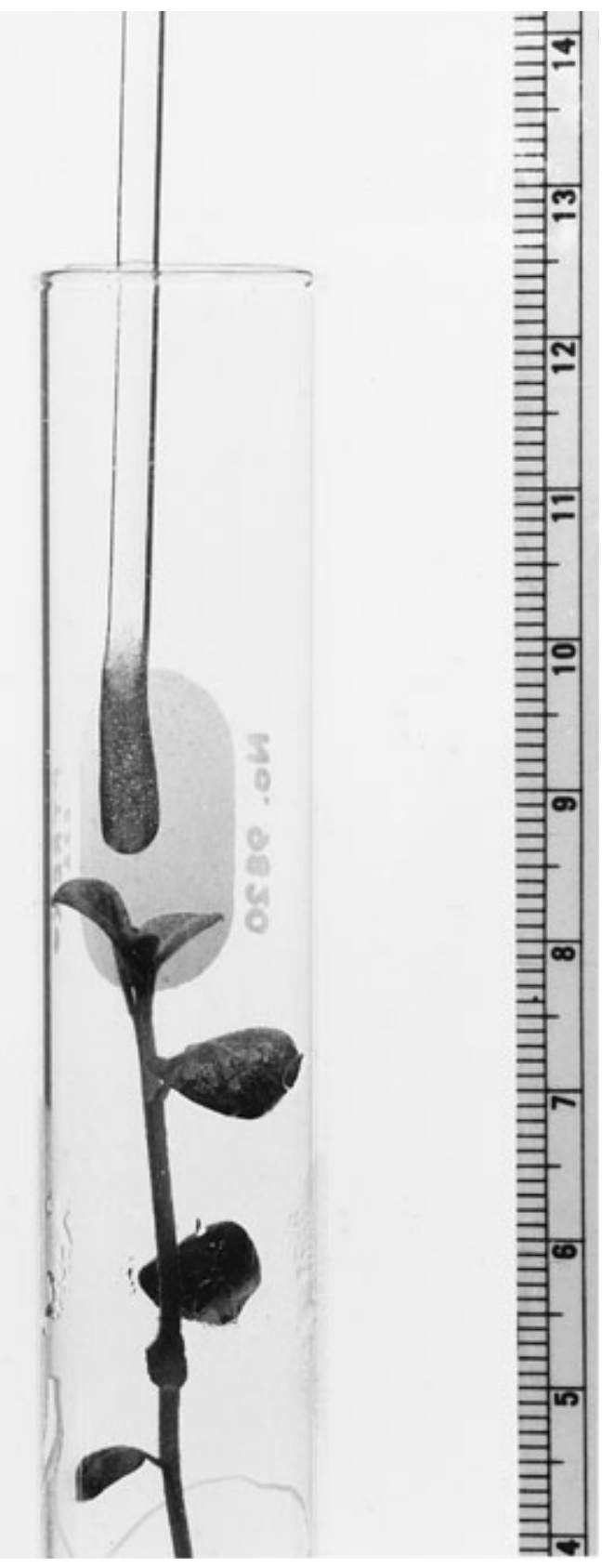

Fig. 1. Mechanical inoculation of an in vitro plantlet using a glass rod impregnated with silicon carbide. in $95 \%$ ethanol, flamed, and allowed to cool between plants. Plants were not removed from culture tubes. Instead, leaves were simply pushed against the inside of the tube with the inoculating rod as it was being rubbed on the plant, but care was taken not to crush the leaves. One week after the initial inoculation, a second mechanical inoculation was performed as before. Inoculated plants were returned to in vitro growth conditions (described above), and 4 weeks after the first inoculation, new growth was tested for virus using the enzyme-linked immunosorbent assay (ELISA).

Mechanical inoculations were performed in the greenhouse on the same lines tested in vitro. In vitro plantlets were transplanted and allowed to grow and acclimatize for 3 to 5 weeks. Inoculations were performed by dusting plant leaves with silicon carbide; three leaves per plant were then rubbed with a cotton swab dipped into a sap extract made from PVY'-infected 'Mex SS 1035' leaves and diluted 1:5 with phosphate buffer. All inoculated leaves were marked, and the silicon carbide was washed off plants 3 to 4 days after inoculation. One week after the initial inoculation, a second mechanical inoculation was performed. Four weeks after the first inoculation, new growth leaves were tested for $\mathrm{PVY}^{\mathrm{o}}$ using ELISA.
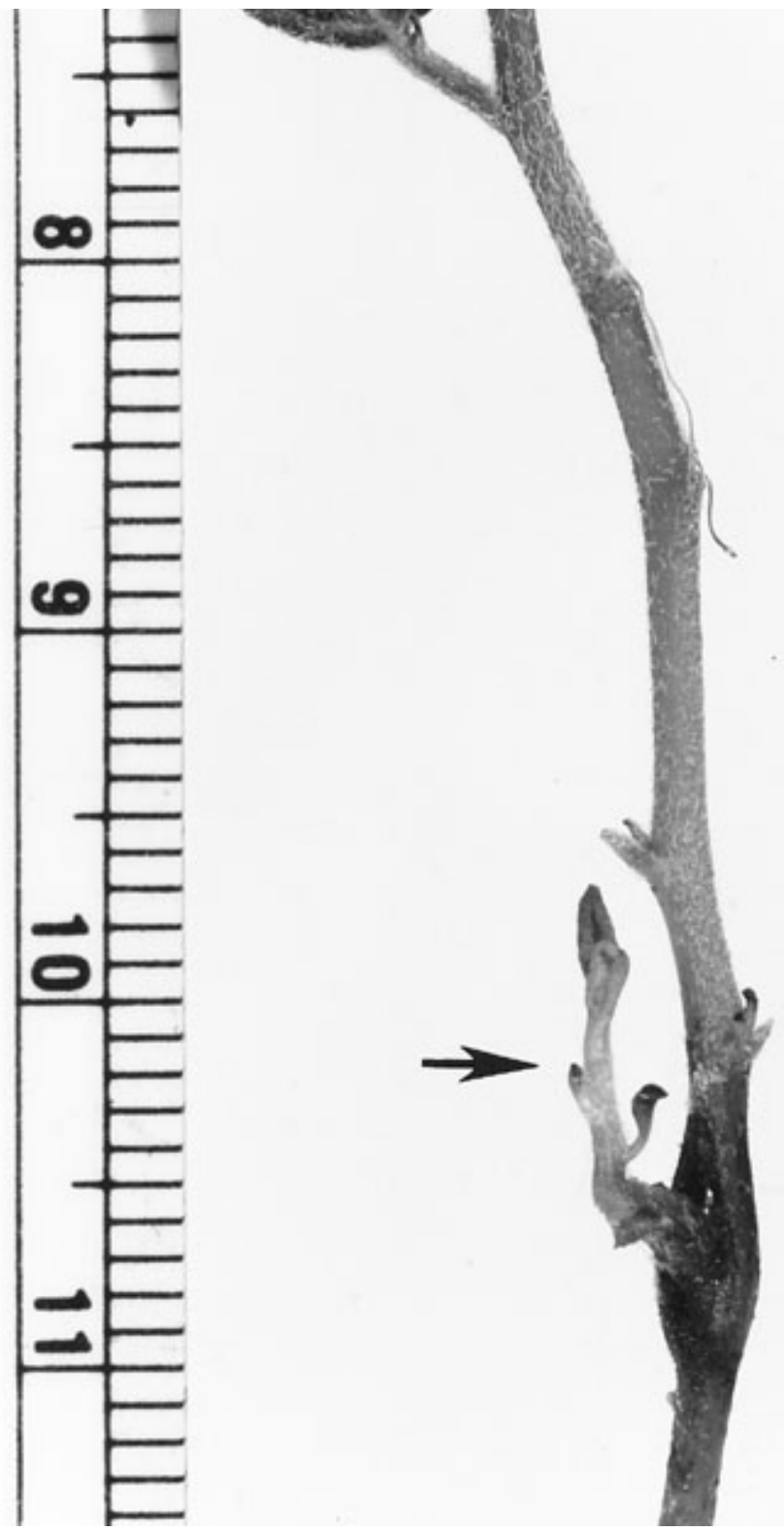

Fig. 2. In vitro graft inoculation showing established scion and infected recipient 4 weeks postinoculation. The arrow on the left points to the potato virus Y strain o-infected scion grafted onto the parental 'Atlantic' potato plant. 
Graft inoculations were performed on in vitro plantlets using a minigraft procedure. Tissue culture plants were partially removed from tubes and rested on sterile filter paper in a laminar flow hood. A 5- to 10-mm slit was cut longitudinally along the lower portion of stems with a sterile scalpel. The tip of the scalpel was inserted into the slit and twisted in order to insert a $\mathrm{PVY}^{\circ}$-infected scion (3 to $5 \mathrm{~mm}$ ) from 'Mex SS 1035 ' potato plants grown in vitro, or a scion from PLRV-infected 'Russet Burbank'. All scions contained a node to allow for growth, which would indicate graft establishment. Cutting and insertion manipulations were kept to a minimum to decrease damage to the graft area. Plantlets were carefully reinserted into culture tubes and grown as before. Because of the relatively high humidity inside culture tubes, no sealants were required around graft junctions or culture tube caps. Grafted plants were sampled for ELISA 4 weeks postinoculation. Scions were collected separately for ELISA to reconfirm scion infection.

Graft inoculations done in the greenhouse were performed on the same lines tested in vitro using PVY ${ }^{\circ}$-infected 'Mex SS 1035' scions. In vitro recipient and scion source plantlets were transferred to the greenhouse and allowed to acclimatize and grow for 3 to 5 weeks. On each recipient, a side graft was made by removing a node from the main stem and replacing it with an infected scion $(3$ to $5 \mathrm{~cm}$ ) containing a node. Parafilm M (American National Can Co., Greenwich, CT) was used to secure scions and decrease dehydration around the graft union. Leaf samples from above the graft junction were taken for ELISA 4 weeks postinoculation. Scions were tested by ELISA separately to reconfirm scion infection.

ELISA methods. Plantlets mechanically and graft-inoculated in vitro were sampled by taking all plant material (leaves and stems) from above inoculated leaves (inoculated leaves were discerned by necrosis caused by abrasion and were not included in the sample) or from above the graft junction (scions were not included). Samples taken from in vitro plantlets ranged in weight from 0.3 to $1.0 \mathrm{~g}$, with the average being $0.5 \mathrm{~g}$; this supplied sufficient sap extracts for approximately 10 ELISA wells when diluted. In vitro samples were crushed on a plant tissue roller-grinder with the addition of $200 \mu \mathrm{l}$ of PBST (0.2 M phosphate-buffered saline, $\mathrm{pH} 7.4$, containing $0.05 \%$ Tween-20) to aid extraction, and approximately 150 to $200 \mu \mathrm{l}$ was collected. Plants used in greenhouse inoculation tests were sampled by taking three leaves from various positions above the point of inoculation (inoculated leaves and scions were not included in these samples). These leaves were also crushed on a roller-grinder, and 150 to $200 \mu \mathrm{l}$ was collected directly. For each ELISA sample, $100 \mu 1$ of sap extract was diluted 1:10 in extraction/conjugation buffer (20 g of polyvinylpyrrolidone, molecular weight 24,000 to 40,000 , and $1 \mathrm{~g}$ of ovalbumin per liter of PBST). The diluted sap extract samples were applied to ELISA plates (100 $\mu \mathrm{l}$ per well and two wells per sample) previously coated overnight at $4{ }^{\circ} \mathrm{C}$ with primary antibody diluted 1:200 with coating buffer $\left(1.59 \mathrm{~g}\right.$ of $\mathrm{Na}_{2} \mathrm{CO}_{3}, 2.93 \mathrm{~g}$ of $\mathrm{NaHCO}_{3}$, and $0.20 \mathrm{~g}$ of $\mathrm{NaN}_{3}$ in 1 liter of $\left.\mathrm{dH}_{2} \mathrm{O}, \mathrm{pH} 9.6\right), 50 \mu \mathrm{l}$ per well; after which, the wells were rinsed three times with PBST. All primary and enzyme-conjugated antibodies used for PVY, CMV, and PLRV ELISA detection came from Agdia Inc., Elkhart, IN. Plant extracts were incubated in wells overnight at $4{ }^{\circ} \mathrm{C}$, and then removed by washing the plate five times with PBST. Alkaline phosphatase-conjugated antibody diluted 1:200 in extraction/conjugation buffer was added to each well $(50 \mu \mathrm{l}$ per well) and incubated at room temperature for $4 \mathrm{~h}$. The wells were washed three times with PBST, and $100 \mu \mathrm{l}$ of substrate reagent (5 mg of $p$-nitrophenyl phosphate disodium in $5 \mathrm{ml}$ of substrate buffer; $9.5 \%$ diethanolamine ( $\mathrm{vol} / \mathrm{vol}$ ), and $200 \mathrm{mg}$ of $\mathrm{NaN}_{3}$ per liter of $\mathrm{dH}_{2} \mathrm{O}$ ) was added per well. Results from separate experiments were standardized by allowing ELISA reactions to develop until a known positive control was approximately 1.5 optical density (OD) units at $405 \mathrm{~nm}$, and then all samples were recorded.

\section{RESULTS}

Figure 1 shows an 'Atlantic' potato plant grown in vitro and the inoculating rod (a glass rod impregnated with silicon carbide at one end) used to mechanically inoculate in vitro plants. The rod is shown being inserted into the tube, and inoculations were performed without removing plants from culture tubes. Figure 2 shows an example of an in vitro minigraft inoculation. The recipient is a parental 'Atlantic' potato plant, and the $P V Y^{\circ}$-infected scion, marked by an arrow, is from a 'Mex SS 1035 ' potato plant. The graft is 3 weeks old and shows a strong scion-recipient union evident by the growing scion. Similar results were seen when PLRVinfected scions from 'Russet Burbank' potato plants were grafted onto 'Atlantic' plants grown in vitro.

Table 1 summarizes the results from in vitro and greenhouse mechanical and graft inoculation experiments done on putative $\mathrm{PVY}^{\circ}$ replicase-mediated resistant transgenic 'Atlantic' lines A1 through A5 and on untransformed parental 'Atlantic'. Parental 'Atlantic' and transgenic lines A2, A4, and A5 reproducibly showed high ELISA values and infection rates in both in vitro and greenhouse tests. Lines A4 and A5 showed some variations in ELISA values and infection rates when greenhouse and in vitro mechanical inoculations were compared, but in vitro and greenhouse graft inoculation results were comparable. Furthermore, all tests suggest that these lines have no appreciable resistance to $\mathrm{PVY}^{\circ}$ infection. In contrast, lines A1 and A3 consistently showed lower mean ELISA values and infection rates from mechanical and graft inoculations performed either in vitro or in a greenhouse. Although graft inoculations performed on A1 and A3 either in vitro or in the greenhouse produced higher ELISA readings and infection rates compared with mechanical inoculations, both A1 and A3 appeared

TABLE 1. Comparison of enzyme-linked immunosorbent assay (ELISA) and infection rate results from greenhouse versus in vitro mechanical and graft inoculation tests of putative potato virus Y strain o $\left(\mathrm{PVY}^{\circ}\right)$-resistant transgenic 'Atlantic' potato lines

\begin{tabular}{|c|c|c|c|c|c|c|c|c|}
\hline \multirow[b]{3}{*}{ Transgenic line designation } & \multicolumn{4}{|c|}{ Mechanical inoculations } & \multicolumn{4}{|c|}{ Graft inoculations } \\
\hline & \multicolumn{2}{|c|}{ Greenhouse } & \multicolumn{2}{|c|}{ In vitro } & \multicolumn{2}{|c|}{ Greenhouse } & \multicolumn{2}{|c|}{ In vitro } \\
\hline & ELISA $^{\mathrm{a}}$ & $\%$ Infection $^{\mathrm{b}}$ & ELISA & $\%$ Infection & ELISA & $\%$ Infection & ELISA & $\%$ Infection \\
\hline A1 & $0.01(0.02)$ & $0[0 / 12]$ & $0.002(0.02)$ & $0[0 / 10]$ & $0.2(0.4)$ & $37[3 / 8]$ & $0.1(0.2)$ & $10[1 / 9]$ \\
\hline A2 & $1.4(0.2)$ & $100[12 / 12]$ & $1.4(0.2)$ & $100[8 / 8]$ & $1.5(0.3)$ & $100[7 / 7]$ & $1.6(0.2)$ & $100[6 / 6]$ \\
\hline A3 & $0.02(0.02)$ & $0[0 / 11]$ & $0.02(0.02)$ & $0[0 / 6]$ & $0.2(0.4)$ & $25[2 / 8]$ & $0.3(0.3)$ & $50[3 / 6]$ \\
\hline A4 & $0.6(0.7)$ & $60[4 / 7]$ & $1.4(0.3)$ & $100[8 / 8]$ & $1.4(0.6)$ & $80[5 / 6]$ & $1.5(0.3)$ & $100[6 / 6]$ \\
\hline
\end{tabular}

${ }^{a}$ Numbers are mean ELISA values calculated from the results of two or three separate experiments. Standard deviations are in parentheses.

${ }^{\mathrm{b}}$ Percent infection rates were determined from the numbers in brackets, which show the number of infected plants over the number inoculated.

c 'Atlantic' mock-inoculated refers to parental 'Atlantic' plants inoculated with only buffer (mechanical) or uninfected scions (graft). Plants were sampled for ELISA 4 weeks postinoculation. 


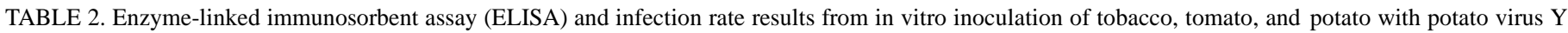
strain o $\left(\mathrm{PVY}^{\circ}\right)$, cucumber mosaic virus strain Fast New York (Fny-CMV), and potato leafroll virus (PLRV)

\begin{tabular}{|c|c|c|c|c|c|c|c|}
\hline \multirow[b]{2}{*}{ Plant type } & \multicolumn{2}{|c|}{$\mathrm{PVY}^{\mathrm{a}}$} & \multicolumn{2}{|c|}{$\mathrm{CMV}^{\mathrm{a}}$} & \multicolumn{2}{|c|}{ PLRV $^{a}$ (graft) } & \multirow{2}{*}{$\frac{\text { Mock inoc. }^{\mathrm{a}}}{\text { ELISA }}$} \\
\hline & ELISA $^{b}$ & $\%$ Infection $^{\mathrm{c}}$ & ELISA & $\%$ Infection & ELISA & $\%$ Infection & \\
\hline Tobacco & $2.4(0.3)$ & $100[4 / 4]$ & $1.6(0.2)$ & $100[4 / 4]$ & & & $0.007(0.003)$ \\
\hline Tomato & $1.3(0.2)$ & $100[4 / 4]$ & $1.7(0.3)$ & $100[4.4]$ & & & $0.002(0.002)$ \\
\hline Potato 'A6'e & $1.9(0.2)$ & $100[4 / 4]$ & $1.0(0.1)$ & $100[4 / 4]$ & & & $0.012(0.004)$ \\
\hline Potato 'Atlantic' & $1.7(0.4)$ & $100[7 / 7]$ & \multicolumn{2}{|c|}{ n.d. } & $1.0(0.4)$ & $88[7 / 8]$ & $0.110(0.010)$ \\
\hline
\end{tabular}

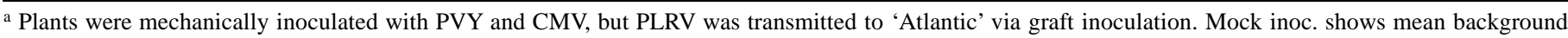
ELISA values from plants (four per plant type) inoculated with only phosphate buffer for mechanical inoculations and healthy scions for graft inoculations.

${ }^{b}$ Numbers are mean ELISA values from the results of one or two experiments. Standard deviations are in parentheses.

c Percent infection rates were determined from the numbers in brackets, which represent the number of infected plants over total number inoculated.

${ }^{\mathrm{d}}$ n.d. = not done

e Potato cultivar A6 (not related to 'Atlantic') was used because most potatoes are resistant to CMV.

to be more resistant to $\mathrm{PVY}^{\mathrm{o}}$ infection via grafting than were parental 'Atlantic' and the other transgenic lines.

To broaden the potential usefulness of in vitro plant virus inoculation testing, tobacco, tomato, and the potato cultivar A6 (unrelated to 'Atlantic') were mechanically inoculated with $\mathrm{PVY}^{\circ}$ and Fny-CMV, and 'Atlantic' plants were graft-inoculated with PLRV. The mean ELISA values and infection rates of plants 4 weeks postinoculation suggest that in vitro techniques can be used to infect tobacco and tomato plants with both $\mathrm{PVY}^{\circ}$ and Fny-CMV (Table 2). In addition, although most potato cultivars are resistant to CMV infection, A6 is not (13) and was clearly infected by Fny-CMV and $P V Y^{\circ}$. 'Atlantic' potato plants were also infected with the phloem-restricted PLRV using minigraft inoculation methods. ELISA values from PLRV-infected plants ranged from $\mathrm{OD}_{405}=$ 0.40 to 1.68 , with the mean being $1.0( \pm 0.4)$ and an infection rate of approximately $88 \%$.

\section{DISCUSSION}

Recombinant DNA and transformation technologies are making significant contributions to the introduction of new genetic traits into plant germ plasm (15). One limiting factor in this new technology is the initial screening of transgenic plants for functional expression of the genetic trait inserted into the plant's genome. For example, the analysis of putative virus-resistant transgenic plants usually requires the testing of a number of independently isolated lines, because transgene expression can vary significantly between transformants. Such screening usually involves laborintensive transplanting of transformed plants from tissue culture to a growth chamber or greenhouse for virus inoculation and subsequent evaluation of virus resistance. The use of growth chambers or greenhouse facilities and materials increases both cost and transgenic plant management, and opens the possibility for pest contamination. This report demonstrates that plants in tissue culture can be reproducibly infected with $\mathrm{PVY}^{\circ}$ by in vitro mechanical and graft inoculation methods. Specifically, putative $\mathrm{PVY}^{\circ}$-resistant transgenic 'Atlantic' lines mechanically and graft-inoculated with $\mathrm{PVY}^{\mathrm{o}}$ showed similar susceptibility and resistance results, as determined by ELISA, compared with clonal sister plants inoculated in the greenhouse. Though the typical $\mathrm{PVY}^{\circ}$ disease symptoms (mosaic leaves) seen on infected plants grown in the greenhouse were not obvious on plants infected in vitro, detection of virus by ELISA was reproducible for both conditions and represents a more objective analysis method. Results from both in vitro and greenhouse screening suggest that transgenic lines A1 and A3 showed the greatest resistance to $\mathrm{PVY}^{\mathrm{O}}$ infection by mechanical and graft methods. Graft inoculation of A1 and A3 did appear to produce higher ELISA readings than mechanical inoculation, but this is probably due to the greater and longer exposure the plant has to virus from the donor scion. Furthermore, ELISA values from A1 and A3 graft inoculations were much lower than the other plants tested. In contrast, lines A2, A4, and A5 appear to have no appreciable resistance to $\mathrm{PVY}^{\mathrm{o}}$. This initial screen suggests that lines A1 and A3 should be further analyzed in field tests. Although it is possible that A2, A4, and A5 may show some resistance to $\mathrm{PVY}^{\mathrm{o}}$ in field trials, these data suggest that this has a low probability. Therefore, efforts should be concentrated on lines that show consistently the lowest ELISA readings (i.e., A1 and A3) and on generating more transgenic lines.

In vitro screening took 3 to 5 weeks less to complete than similar greenhouse testing (total time for in vitro screening including plant propagation, inoculation, and ELISA was 6 to 7 weeks), and used less than $1 / 10$ the space required for greenhouse plants (more than 100 plants were tested in both situations). The conditions used to grow and test plants in vitro (e.g., room temperature, timer-controlled fluorescent lights, laminar flow hoods, and sterile techniques) minimized pest contamination, which is more difficult and expensive to control in growth chambers and greenhouses.

The potential usefulness of in vitro virus-resistance screening was extended by showing that tomato, tobacco, and potato plants could be infected with CMV and PVY ${ }^{\circ}$ using in vitro mechanical inoculation methods. CMV and PVY infection rates for tobacco, tomato, and potato plants mechanically inoculated in vitro were $100 \%$, and infected plants displayed ELISA values much higher than background readings. This suggests that mechanically inoculated plants can become infected with $\mathrm{PVY}^{\circ}$ at high rates, and the infection can readily be detected by ELISA. Furthermore, in vitro minigraft techniques were able to transmit the relatively lowtiter phloem-restricted PLRV to 'Atlantic' potato plants. In this case, the infection rate was $88 \%$, and enough virus was present in infected plants to produce unambiguous ELISA results. For example, individual infected plants generated ELISA values ranging in value from $\mathrm{OD}_{405}=0.40$ to 1.68 , with a mean value of $1.0 \pm 0.4$. Previous work in our laboratory (10) showed PLRV controls at 250 $\mathrm{ng} / \mathrm{ml}$ generated $\mathrm{OD}_{405}=1.5$ under similar conditions. In summary, it appears that plants infected in vitro generate sufficient virus and sample material to allow reliable detection of PVY, CMV, and the low-titer virus PLRV by ELISA. Therefore, it may be possible to screen for the resistance of plants to these and other viruses in vitro.

Though in vitro screening of putative virus-resistant transgenic plants can only augment eventual greenhouse and field testing, this report suggests that it can be an efficient initial selection method, which could significantly reduce the time and cost of transgenic plant development. Furthermore, in vitro methods may have utility in the screening of not only transgenic plants, but different genotypes within a plant species for other traits of interest (e.g., resistance to other pathogens, herbicides, high salinity, etc.).

\section{LITERATURE CITED}

1. Audy, P., Palukaitis, P., Slack, S. A., and Zaitlin, M. 1994. Replicasemediated resistance to potato virus $\mathrm{Y}$ in transgenic tobacco plants. Mol. Plant-Microbe Interact. 7:15-22.

2. Bates, G. W. 1994. Genetic transformation of plants by protoplast electroporation. Mol. Biotechnol. 2:135-145. 
3. Fraley, R. T., Rogers, S. G., Horsch, R. B., Sanders, P. R., Flick, J. S., Adams, S. P., Bittner, M. L., Brand, L. A., Fink, C. L., Fry, J. S., Galluppi, G. R., Goldberg, S. B., Hoffmann, N. L., and Woo, S. C. 1983. Expression of bacterial genes in plant cells. Proc. Natl. Acad. Sci. U.S.A. 80:4803-4807.

4. Gamborg, O. L., and Phillips, G. C., eds. 1995. Plant Cell, Tissue and Organ Culture. Springer-Verlag, Berlin.

5. Glick, R. B., and Thompson, J. E., eds. 1993. Methods in Plant Molecular Biology and Biotechnology. CRC Press, Boca Raton, FL.

6. Grant, J. E., Dommisse, E. M., Christey, M. C., and Conner, A. J. 1991. Gene transfer to plants using Agrobacterium. Pages 50-73 in: Advanced Methods in Plant Breeding and Biotechnology. D. R. Murry, ed. CAB International, Oxon, England.

7. Hoekema, A., Hirsch, P. R., Hooykaas, P. J. J., and Schilperoort, R. A. 1983. A binary plant vector strategy based on separation of the vir and T regions of Agrobacterium tumefaciens Ti plasmid. Nature 303:179-180

8. Innis, M. A., Gelfand, D. H., Sninsky, J. J., and White, T. J., eds. 1990. PCR Protocols: A Guide to Methods and Applications. Academic Press, New York.
9. Potrykus, I., and Spangenberg, G., eds. 1995. Gene Transfer to Plants. Springer-Verlag, Berlin

10. Sanchez, G. E. 1993. Materials and Methods. Pages 24-25 in: Assessment of potato leafroll virus resistance by acquisition and inoculation periods in a greenhouse microplot system. Ph.D. thesis. Cornell University, Ithaca, NY.

11. Sanford, J. C., Klein, T. M., Wolf, E. D., and Allen, N. 1987. Delivery of substances into cells and tissues using a microprojectile bombardment process. J. Particle Sci. Technol. 5:27-37.

12. Schardl, C. L., Byrd, A. D., Benzion, G., Altschuler, M. A., Hildebrand, D. F., and Hunt, A. G. 1987. Design and construction of a versatile system for the expression of foreign genes in plants. Gene 61:1-11.

13. Valkonen, J. P., Slack, S. A., and Watanabe, K. N. 1995. Resistance to cucumber mosaic virus in potato. Ann. Appl. Biol. 126:143-151.

14. Wang, K., Herrera-Estrella, A., and Van Montague, M., eds. 1995. Transformation of Plants and Soil Microorganisms. Cambridge University Press, New York.

15. Watanabe, K. N., and Pehu, E., eds. 1997. Plant Biotechnology and Plant Genetic Resources for Sustainability and Productivity. Academic Press, Austin, TX. 